\title{
Identifikasi Sebaran Batuan Beku Di Bukit Koci Desa Sempalai Kabupaten Sambas Kalimantan Barat Dengan Menggunakan Metode Geolistrik Resistivitas
}

\author{
Mimin Setiadia), Apriansyahb), Joko Sampurno ${ }^{\mathrm{a})^{*}}$
}

\author{
aJurusan Fisika, bJurusan Ilmu Kelautan, Fakultas Matematika dan Ilmu pengetahuan Alam \\ Universitas Tanjungpura \\ Jalan Prof. Dr. Hadari Nawawi, Pontianak, Indonesia \\ *Email : jokosampurno@physics.untan.ac.id
}

\begin{abstract}
Abstrak
Telah dilakukan penelitian tentang identifikasi sebaran batuan beku dibukit Koci Desa Sempalai Kabupaten Sambas Kalimantan Barat dengan menggunakan metode geolistrik resistivitas. Penelitian ini bertujuan untuk mendapatkan nilai resistivitas batuan dan mengetahui pola sebaran serta jenis batuan yang ada di lokasi penelitian. Penelitian dilakukan dengan membuat 6 buah lintasan geolistrik yang dimana 5 lintasan berada di puncak bukit dan 1 lintasan di lembah bukit. Berdasarkan hasil pengolahan data dari keenam lintasan menunjukkan bahwa jenis batuan yang mendominasi pada daerah penelitian adalah pasir, batu pasir, dan batuan beku andesit. Batuan beku andesit tersebar pada puncak bukit dengan lintasan 1,2,3,4, dan 6 .
\end{abstract}

Kata kunci : Bukit Koci, Batuan Beku, Geolistrik Resistivitas

\section{Latar Belakang}

Sejalan dengan pesatnya perkembangan dan dimulainya era perbaikan disegala bidang baik industri, perdagangan maupun pariwisata tentunya akan disertai dengan pembangunan infrastruktur seperti jalan, jembatan, perkantoran dan sebagainya. Pembangunan sarana akses transportasi yang menghubungkan kabupaten sambas dengan daerah lainnya merupakan suatu usaha untuk memberikan akses informasi, ekonomi, sosial dan budaya yang lancar, cepat dan aman.

Untuk menunjang pembangunan tersebut, diperlukan berbagai data dan informasi, salah satunya adalah data tentang jenis batuan. Informasi jenis batuan lebih spesifiknya mempelajari kualitas batuan yang akan menentukan tata guna wilayah yang hendak dilakukan rekayasa pembangunan, dalam hal ini dapat membantu perancang kontruksi dalam penggunaan wilayah serta material yang akan digunakan sebagai bahan bangunan [1].

Dari jenis batuan yang ada, Kabupaten Sambas terbentuk oleh endapan Alluvium, Litoral, dan endapan limpah banjir dan pada daerah yang lebih tinggi dibentuk oleh pelapukan satuan batuan formasi Seminis. Batuan endapan alluvium tersusun dari sedimen klastik dan alluvium dan merupakan hasil dari endapan terrestrial alluvium. Sedangkan batuan endapan litoral tersusun dari sedimen klastik dan fine dan merupakan hasil dari endapan litoral dan estuary.
Batuan dapat diketahui dengan mengetahui nilai tahanan jenisnya terlebih dahulu. Dalam hal ini, dapat diaplikasikan metode geofisika. Salah satu metode geofisika yang dapat digunakan dalam identifikasi batuan bawah permukaan adalah metode geolistrik resistivitas. Metode geolistrik adalah metode geofisika yang dapat menggambarkan keberadaan batuan atau mineral di bawah permukaan berdasarkan sifat kelistrikan dari batuan atau mineralnya. Resistivitas batuan bawah permukaan dapat dihitung dengan mengetahui besar arus yang dipancarkan melalui elektroda dan besar potensial yang dihasilkan. Untuk mengetahui struktur bawah permukaan yang lebih dalam, maka jarak masing-masing elektroda arus dan elektroda potensial ditambah secara bertahap. Semakin besar spasi/jarak elektroda arus maka efek penembusan arus ke bawah makin dalam, sehingga batuan yang lebih dalam akan dapat diketahui sifat-sifat fisisnya [2]. Pada penelitian ini, akan menggunakan metode geofisika untuk mengidentifikasi sebaran batuan beku yang yang ada di Bukit Koci Desa Sempalai Kabupaten Sambas Kalimantan Barat.

\section{Metodologi}

\subsection{Metode Geolistrik Tahanan Jenis} (Resistivitas)

Metode geolistrik merupakan salah satu metode geofisika yang mempelajari sifat aliran listrik di dalam bumi dan bagaimana cara mendeteksinya di permukaan bumi. Dalam hal ini 
meliputi pengukuran potensial dan pengukuran arus yang terjadi baik secara alamiah maupun akibat injeksi arus kedalam bumi. Oleh karena itu metode geolistrik mempunyai banyak macam, salah satunya adalah metode geolistrik tahanan jenis (resistivitas) [3].

Tujuan dari survei geolistrik adalah untuk menentukan distribusi resistivitas dibawah permukaan dengan membuat pengukuran di permukaan tanah. Pengukuran resistivitas secara normal dibuat dengan cara menginjeksikan arus ke dalam tanah melalui dua elektroda arus, dan mengukur Beda tegangan yang dihasilkan pada dua elektroda potensial. Dari pengukuran ini resistivitas yang sebenarnya dari bawah permukaan dapat diperkirakan. Resistivitas tanah berkaitan dengan berbagai parameter geologi seperti mineral dan konten cairan, porositas, derajat patahan, persentase dari patahan diisi dengan air tanah dan derajat dari saturasi air di batuan [4].

Berdasarkan hukum Ohm diketahui bahwa besar tegangan $V$ (volt) suatu material bergantung pada kuat arus $I$ (ampere) dan hambatan listrik $R$ (ohm) yang dirumuskan sebagai berikut:

$V=I R$

Studi hambatan listrik dari geofisika dapat dipahami dalam konteks dari aliran arus melalui medium di bawah permukaan yang terdiri dari lapisan bahan dengan resistivitas yang berbeda. Untuk sederhananya, semua lapisan diasumsikan horisontal. Resistivitas $\rho$ dari bahan adalah pengukuran seberapa baik bahan menghambat aliran arus listrik [5].

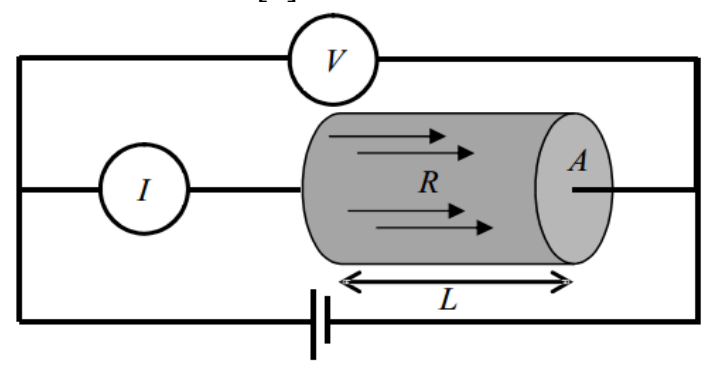

Gambar 1. Arus yang dialirkan pada material konduktif berbentuk silinder [5].

Suatu material konduktif berbentuk silinder yang homogen memiliki panjang sebesar L serta luas penampang A maka resistivitasnya sebesar:
$\rho=R \frac{A}{L}$

Dari persamaan (1) dan persamaan (2) jika disubstitusi persamaanya akan menjadi:

$\rho=\frac{V}{I} \frac{A}{L}$

Dimana :

$$
\begin{aligned}
V & =\text { Beda potensial (volt) } \\
I & =\text { Kuat arus yang melalui bahan (Ampere) } \\
R & =\text { Resistansi }(\Omega) \\
\rho & =\text { Resistivitas }(\Omega \mathrm{m}) \\
L & =\text { Panjang medium (meter) } \\
A & =\text { Luas medium (meter }^{2} \text { ) }
\end{aligned}
$$

\subsection{Resistivitas Batuan}

Resistivitas batuan bervariasi menurut jenis batuan, porositas dan kandungan fluida (minyak, air, gas). Kebanyakan mineral membentuk batuan penghantar listrik yang tidak baik walaupun beberapa logam asli dan grafik menghantarkan listtrik resistivitas yang terukur. Pada material bumi utamanya ditentukan oleh pergerakan ionion bermuatan dalam pori-pori fluida. Air tanah secara umum berisi campuran terlarut yang dapat menambah kemampuan untuk menghantar listrik, meskipun air tanah bukan konduktor listrik yang baik variasi resistivitas material [6].

\subsection{Konfigurasi Wenner-Schlumberger}

Konfigurasi Wenner-Schlumberger adalah konfigurasi dengan sistem aturan spasi yang konstan dengan catatan faktor " $n$ " untuk konfigurasi ini adalah perbandingan jarak antara elektroda A-M (atau B-N) adalah 2na $a$. Proses penentuan resistivitas menggunakan 4 buah elektroda yang diletakkan dalam sebuah garis lurus [7].

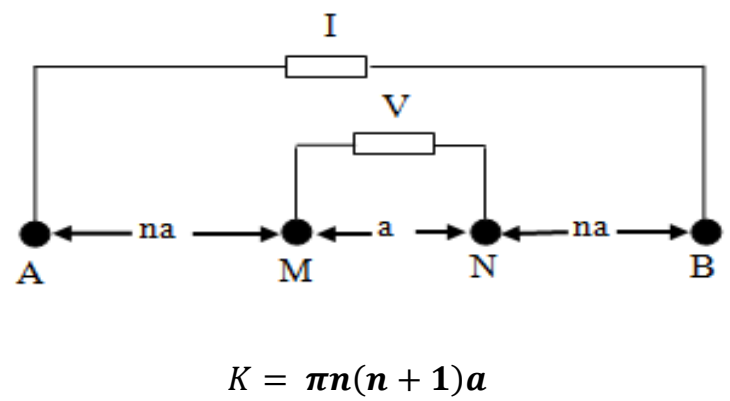

Gambar 2. Elektroda konfigurasi Wenner Schlumberger [7] 
Nilai resistivitas untuk metode WennerSchlumberger dapat dihitung dengan factor geometri.

$$
\rho=k \frac{\Delta V}{I}
$$

dengan $k=\pi n(n+1) a$

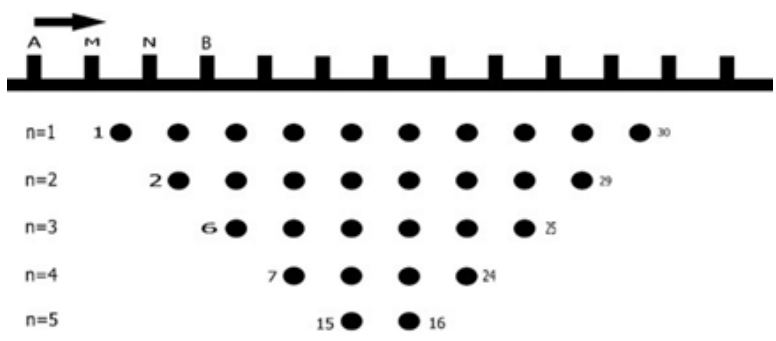

Gambar 3. Stacking Chart konfigurasi Wenner Schlumberger [7].

Faktor geometri K merupakan besaran yang berubah terhadap jarak spasi elektroda dan tergantug pada konfigurasi elektroda. Faktor geometri untuk masing-masing konfigurasi mempunyai nilai yang berbeda.

\subsection{Lokasi dan Prosedur Penelitian}

Penelitian ini bersifat eksperimental yang berupa pemodelan fisis batuan yang langsung dilaksanakan di lapangan dengan menggunakan skala model. Penelitian ini dilakukan di Bukit Koci Desa Sempalai Kabupaten Sambas Kalimantan Barat.

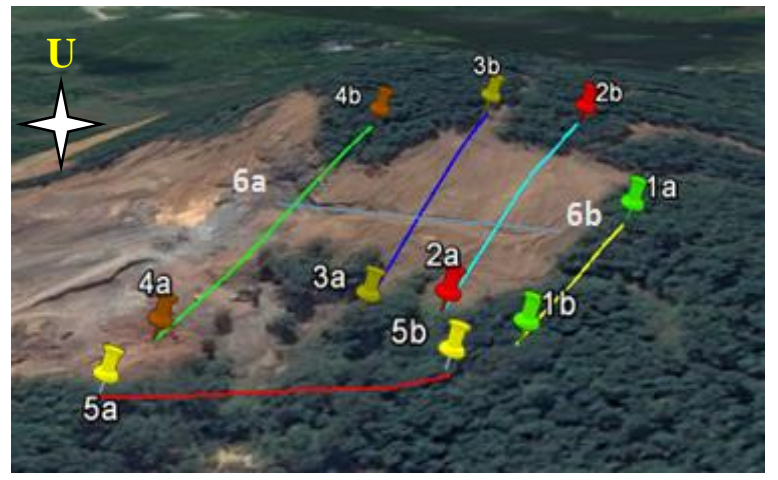

Gambar 4. Lokasi Penelitian [8]

Metode yang digunakan untuk Penelitian tentang identifikasi batuan ini menggunakan metode geolistrik resistivitas dengan konfigurasi wenner-schlumberger sebanyak 6 lintasan. Lintasan penelitian 2,3,4 dan 6 masing-masing sepanjang 160 meter dan lintasan 1 dan 5 masingmasing sepanjang 120 meter.

Pada penelitian ini penulis menggunakan alat geolistrik laboratorium fisika dasar Fmipa UNTAN yaitu berupa resistivity meter merk ARES Resistivity. ARES ini berfungsi sebagai transmitter (pemberi sinyal arus) dan sebagai receiver (penerima sinyal tegangan) serta memberikan informasi tentang arus yang diberikan, beda potensial yang terukur, hingga nilai resistivitas semu dari hasil pengukuran. Pada proses akuisisi data menggunakan resistivity meter ini, nilai faktor rasio otomatis ditentukan oleh alat sesuai dengan design pengukuran yang dibuat.

Hasil nilai resistivitas semu bahan yang didapat pada lokasi penelitian diolah dengan menggunakan perangkat lunak Res2Dinv 3.54 dan akan didapatkan gambaran berupa penampang nilai resistivitas dari setiap lintasan pengukuran yang digunakan untuk interprestasi jenis dan sebaran batuan beku. Untuk mengetahui jenisjenis material pada lokasi penelitian akan didapatkan dari penampang resistivitas hasil dari pengolahan Res2Dinv 3.54 dan tabel nilai resistivitas.

Tabel 1. Nilai Resistivitas Fluida Dan Batuan [9]

\begin{tabular}{cc}
\hline Material Bumi & $\begin{array}{c}\text { Resistivitas Bumi } \\
\text { Ohm-m }\end{array}$ \\
\hline Batuan sedimen & $10-10^{3}$ \\
Batu lempung & $1-10^{8}$ \\
Batu Pasir & $50-10^{7}$ \\
Batu Gamping & $100-10^{4}$ \\
Dolomite & $1-10^{3}$ \\
Sedimen Lepas & $1-10^{2}$ \\
Pasir & \\
Lempung & $10^{2}-10^{6}$ \\
Batuan kristalin & $10^{4}-10^{5}$ \\
Granit & $10^{3}-10^{6}$ \\
Diorite & $10^{2}-10^{4}$ \\
Gabbro & $10-10^{7}$ \\
Andesit & $10-10^{4}$ \\
Basalt & $10^{4}-10^{6}$ \\
Sekis &
\end{tabular}




\section{3}

\section{Hasil dan pembahasan}

Penelitian tentang identifikasi sebaran batuan ini dilakukan pada Bukit Koci Desa Sempalai Kabupaten Sambas, dengan daerah penelitian sendiri merupakan bukit bebatuan, hal itu dapat dibuktikan dengan banyaknya singkapan batuan yang terdapat pada lokasi penelitian.

Untuk jenis-jenis batuan yang didapatkan dari lokasi penelitian antara lain tanah lempung atau biasa disebut tanah liat merupakan tanah dengan kadar mineral lempung yang tinggi, Tanah jenis ini memiliki leburan silica yang sangat halus. Lempung terbentuk dari proses pelapukan silica oleh asam karbonat dan sebagian dihasilkan oleh aktivitas panas bumi, dengan nilai resistivitas pada tabel nilai resistivitas adalah $1 \Omega \mathrm{m}-100 \Omega \mathrm{m}$.

Batuan yang kedua yaitu pasir. Pasir merupakan batuan sedimen yang mempunyai bentuk berupa butiran-butiran kecil dengan nilai resistivitas pada tabel nilai resistivitas adalah $1 \Omega \mathrm{m}-1000 \Omega \mathrm{m}$.

Untuk batuan yang ketiga yaitu batupasir (sandstone). Batupasir merupakan batuan sedimen yang berasal dari pasir yang telah mengalami kompaksi dan memiliki tekstur permukaan yang kasar. Pada tabel nilai resistivitas batupasir memiliki rentang nilai yang berkisar $200 \Omega \mathrm{m}-8000 \Omega \mathrm{m}$.

Untuk batuan yang keempat adalah batuan beku andesit. Batuan ini merupakan jenis batuan beku vulkanik yang terbentuk dari pembekuan lava yang keluar ke permukaan bumi saat letusan gunung berapi. Batuan andesit memiliki tekstur porfiritik dengan fenokris yang euhedral dan juga memiliki kekerasan yang sangat kuat, dengan rentang nilai pada tabel resistivitas $100 \Omega \mathrm{m}$ $10000 \Omega \mathrm{m}$

\subsection{Hasil Penampang Resistivitas Pada Lintasan 1}

Lintasan pertama berada pada koordinat 49N 297588 E 138799 N dengan lintasan sepanjang $120 \mathrm{~m}$ dan elektroda sebanyak 24 buah dengan jarak masing - masing elektroda $5 \mathrm{~m}$. Hasil dari pegukuran berupa gambaran nilai resistivitas yang diolah menggunakan perangkat lunak Res2Dinv 3.54 dapat dilihat pada Gambar 5.

Berdasarkan hasil yang didapat pada Gambar 5 dengan panjang lintasan $120 \mathrm{~m}$ dan hasil pengukuran mencapai kedalaman 19,8 m. Jenis batuan pertama dengan rentangan nilai resistivitas berkisar 35,9 $\Omega \mathrm{m}-159 \Omega \mathrm{m}$, nilai ini diinterprestasikan sebagai pasir (sand).

Jenis batuan kedua dengan rentang nilai resistivitas dari kisaran $334 \Omega \mathrm{m}-1480 \Omega \mathrm{m}$ dapat diasumsikan sebagai batupasir (sandstone).

Jenis batuan yang ketiga, dengan rentang nilai resistivitas berkisar $3115 \Omega \mathrm{m}-6554 \Omega \mathrm{m}$ dapat diasumsikan sebagai batuan andesit. Batuan beku andesit pada lintasan ini terdapat pada sepanjang lintasan dari rentang $15 \mathrm{~m}-100 \mathrm{~m}$, dan berada pada kedalaman 1,25 m - 15,9 m dari permukaan tanah.

\subsection{Hasil Penampang Resistivitas Pada Lintasan 2}

Hasil dari pengukuran lintasan kedua berupa gambaran nilai resistivitas yang diolah menggunakan perangkat lunak Res2Dinv 3.54 dapat dilihat pada Gambar 6. Lintasan kedua berada pada koordinat 49N 297542 E $138799 \mathrm{~N}$ dengan lintasan sepanjang $160 \mathrm{~m}$ dan elektroda sebanyak 32 buah dengan jarak masing-masing elektroda $5 \mathrm{~m}$.

Berdasarkan hasil yang didapat Gambar 6 dengan panjang lintasan $160 \mathrm{~m}$ dan hasil pengukuran mencapai kedalaman $28.7 \mathrm{~m}$. Didapatkan rentang nilai resistivitas yang berbeda-beda dari yang terkecil dengan nilai resistivitas $184 \Omega \mathrm{m}$ sampai yang terbesar mencapai $9578 \Omega \mathrm{m}$. Jenis batuan pertama dengan resistivitas rendah yaitu memiliki rentangan nilai resistivitas berkisar $184 \Omega \mathrm{m}-324 \Omega \mathrm{m}$, nilai ini diinterprestasikan sebagai pasir (sand).

Jenis batuan kedua, dengan rentang nilai resistivitas berkisar $570 \Omega \mathrm{m}-1762 \Omega \mathrm{m}$ dapat diasumsikan sebagai batupasir (sandstone).

Jenis batuan yang ketiga, dengan rentang nilai resistivitas berkisar $3098 \Omega \mathrm{m}-9578 \Omega \mathrm{m}$ dapat diasumsikan sebagai batuan andesit. Batuan beku andesit terdapat dua bagian sepanjang lintasan 2, bagian pertama terdapat pada rentang $10 \mathrm{~m}-60 \mathrm{~m}$ dan berada pada kedalaman 1,25 m $24 \mathrm{~m}$. bagian kedua terdapat pada rentang $85 \mathrm{~m} \mathrm{-}$ $125 \mathrm{~m}$ dan berada pada kedalaman 1,25 m - 28,7 $\mathrm{m}$.

\subsection{Hasil Penampang Resistivitas Pada Lintasan 3 \\ Gambar 7 merupakan Hasil dari} pengukuran lintasan ketiga yang berupa gambaran penampang nilai resistivitas dan diolah menggunakan perangkat lunak Res2Dinv 3.54.

Lintasan ketiga berada pada koordinat 49N 297544 E 138828 N dengan lintasan sepanjang $160 \mathrm{~m}$ dan elektroda sebanyak 32 buah dengan jarak masing-masing elektroda $5 \mathrm{~m}$.

Berdasarkan hasil yang didapat pada lintasan 3 dengan panjang $160 \mathrm{~m}$ dan hasil pengukuran mencapai kedalaman $28.7 \mathrm{~m}$. 
Didapatkan rentang nilai resistivitas yang berbeda-beda dari yang terkecil dengan nilai resistivitas $30.2 \Omega \mathrm{m}$ sampai yang terbesar mencapai $3073 \Omega \mathrm{m}$. Jenis batuan pertama dengan resistivitas rendah yaitu memiliki rentangan nilai resistivitas berkisar $30.2 \Omega \mathrm{m}-113 \Omega \mathrm{m}$, nilai ini diinterprestasikan sebagai pasir (sand).

Jenis batuan kedua, dengan rentang nilai resistivitas dengan kisaran $219 \Omega \mathrm{m}-821 \Omega \mathrm{m}$ diasumsikan sebagai batupasir (sandstone).

Jenis batuan yang ketiga, dengan rentang nilai resistivitas berkisar $1588 \Omega \mathrm{m}-3073 \Omega \mathrm{m}$ dapat diasumsikan sebagai batuan andesit. Pada lintasan ini memperlihatkan bahwa batuan beku andesit tersebar hampir sepanjang lintasan 3 dari rentang $30 \mathrm{~m}-150 \mathrm{~m}$ dan berada pada kedalaman 1,25 m-28,7 m.

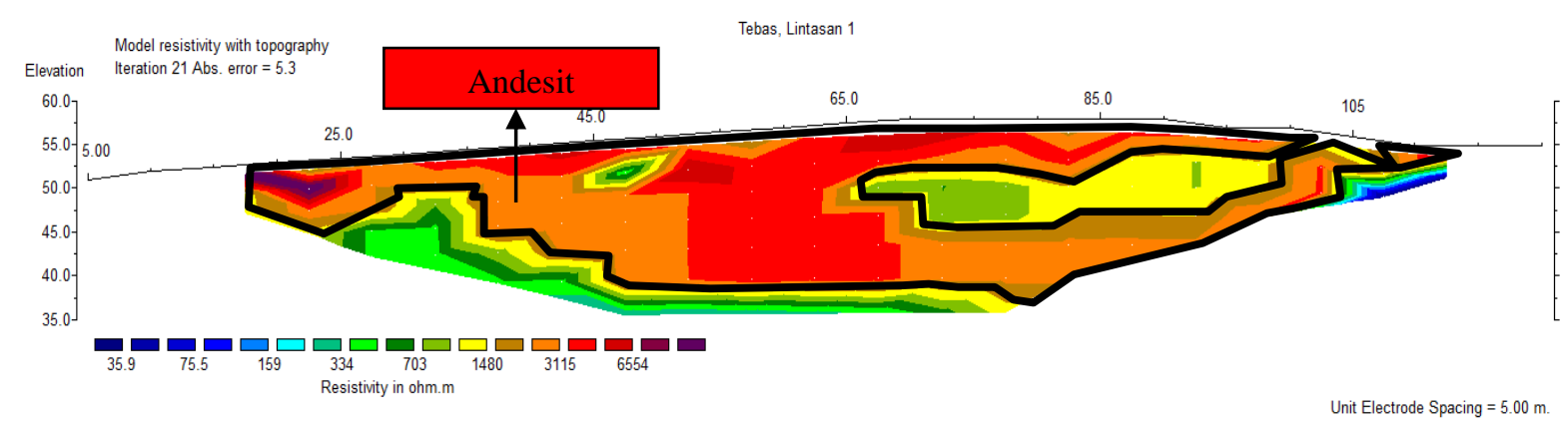

Gambar 5. Penampang resistivitas pada lintasan 1

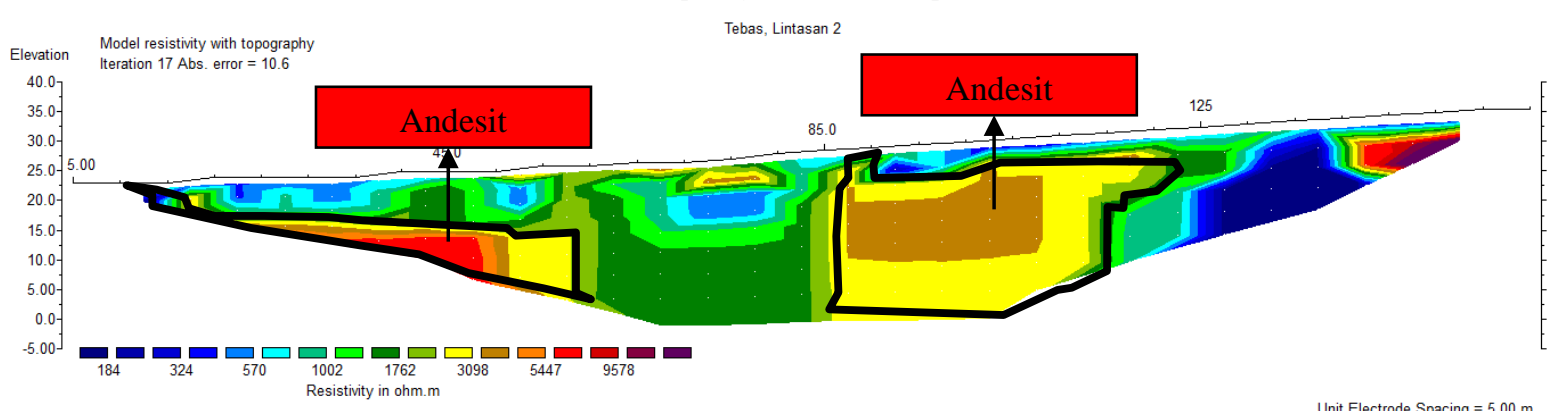

Gambar 6. Penampang resistivitas pada lintasan 2

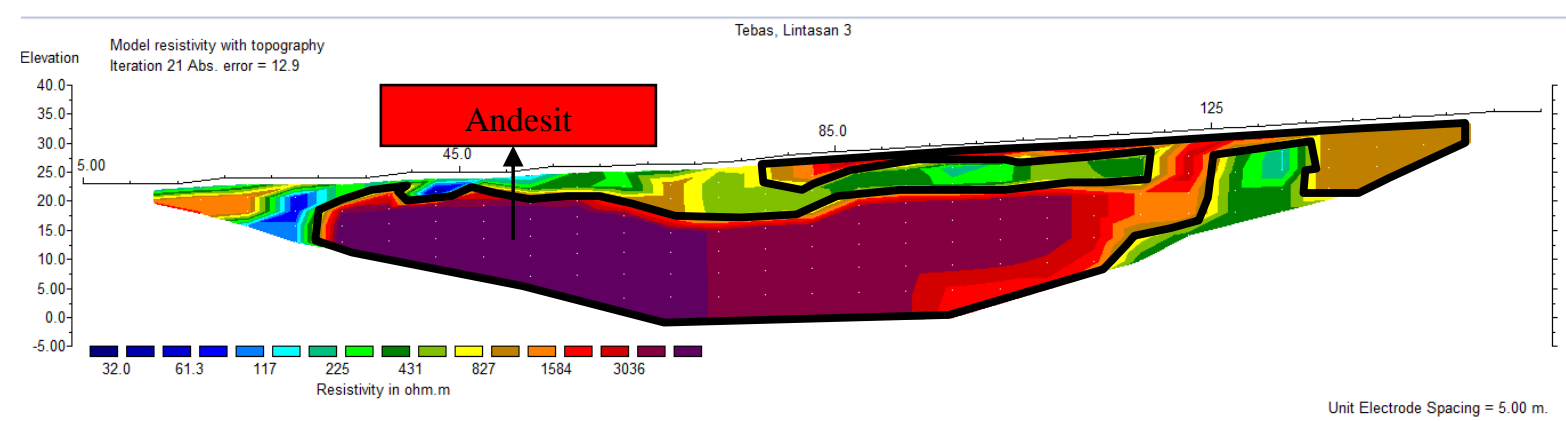

Gambar 7. Penampang resistivitas pada lintasan 3

\subsection{Hasil Penampang Resistivitas Pada Lintasan 4 \\ Hasil dari pengukuran lintasan keempat} berupa gambaran nilai resistivitas yang diolah menggunakan perangkat lunak Res2Dinv 3.54 dapat dilihat pada Gambar 8. Lintasan keempat berada pada koordinat 49N 297528 E $138900 \mathrm{~N}$ dengan lintasan sepanjang $160 \mathrm{~m}$ dan elektroda sebanyak 32 buah dengan jarak masing-masing elektroda $5 \mathrm{~m}$.

Berdasarkan hasil yang didapat Gambar 8 pada lintasan 4 dengan panjang $160 \mathrm{~m}$ dan hasil pengukuran mencapai kedalaman $28.7 \mathrm{~m}$. Jenis batuan pertama dengan resistivitas rendah yaitu memiliki rentangan nilai resistivitas berkisar 
74,6 $\Omega \mathrm{m}-276 \Omega \mathrm{m}$, nilai ini diinterprestasikan sebagai pasir (sand).

Jenis batuan kedua, dengan rentang nilai resistivitas berkisar $531 \Omega \mathrm{m}-1021 \Omega \mathrm{m}$ dapat diasumsikan sebagai batupasir (sandstone).

Jenis batuan yang ketiga, dengan rentang nilai resistivitas berkisar $1953 \Omega \mathrm{m}-7260 \Omega \mathrm{m}$ dapat diasumsikan sebagai batuan andesit. Batuan ini terdapat dua bagian sepanjang lintasan 4, bagian pertama terdapat pada rentang $10 \mathrm{~m}-85$ $\mathrm{m}$ dan berada pada kedalaman 1,25 $\mathrm{m}-15,9 \mathrm{~m}$. Bagian kedua terdapat pada rentang $95 \mathrm{~m}-150 \mathrm{~m}$ dan berada pada kedalaman 1,25 m - 15,9 m.

\subsection{Hasil Penampang Resistivitas Pada Lintasan 5}

Gambar 9 merupakan Hasil dari pengukuran lintasan kelima yang berupa gambaran penampang nilai resistivitas dan diolah menggunakan perangkat lunak Res2Dinv 3.54.

Lintasan kelima berada pada koordinat 49N 297493 E $138906 \mathrm{~N}$ dengan lintasan sepanjang $120 \mathrm{~m}$ dan elektroda sebanyak 24 buah dengan jarak masing-masing elektroda $5 \mathrm{~m}$. Lintasan ini berada dikaki bukit tempat pengukuran dengan posisi mengarah ke utara dan berjarak $40 \mathrm{~m}$ dari lintasan 1,2,3 dan 4.

Berdasarkan hasil yang didapat pada Gambar 9 dengan panjang lintasan $120 \mathrm{~m}$ dan hasil pengukuran mencapai kedalaman 19,8 m. Jenis pertama dengan resistivitas rendah yaitu memiliki rentangan nilai resistivitas berkisar $26,8 \Omega \mathrm{m}-52,5 \Omega \mathrm{m}$, nilai ini diinterprestasikan sebagai tanah lempung (clay).

Jenis batuan kedua, dengan rentang nilai resistivitas berkisar $103 \Omega \mathrm{m}-396 \Omega \mathrm{m}$ dapat diasumsikan sebagai pasir (sand).

Jenis batuan ketiga, dengan rentang nilai resistivitas berkisar $776 \Omega \mathrm{m}-2984 \Omega \mathrm{m}$ dapat diasumsikan sebagai batupasir (sandstone).

\subsection{Hasil Penampang Resistivitas Pada Lintasan 6}

Lintasan keenam berada pada koordinat 49 N297607 E 138880 N dengan lintasan sepanjang $160 \mathrm{~m}$ dan elektroda sebanyak 32 buah dengan jarak masing-masing elektroda $5 \mathrm{~m}$. Hasil dari pengukuran berupa gambaran nilai resistivitas yang diolah menggunakan perangkat lunak Res2Dinv 3.54 dapat dilihat pada Gambar 10.

Berdasarkan hasil yang didapat Gambar 10 pada lintasan 6 dengan panjang $160 \mathrm{~m}$ dan hasil pengukuran mencapai kedalaman 28,7 m. didapatkan rentang nilai resistivitas yang berbeda-beda dari yang terkecil dengan nilai resistivitas $42,1 \Omega \mathrm{m}$ sampai yang terbesar mencapai $2348 \Omega \mathrm{m}$. Jenis batuan pertama dengan resistivitas rendah yaitu memiliki rentangan nilai resistivitas berkisar $42,1 \Omega \mathrm{m}-113 \Omega \mathrm{m}$, nilai ini diinterprestasikan sebagai pasir (sand).

Jenis batuan kedua, dengan rentang nilai resistivitas berkisar $236 \Omega \mathrm{m}-744 \Omega \mathrm{m}$ dapat diasumsikan sebagai batupasir (sandstone).

Jenis batuan yang ketiga, dengan rentang nilai resistivitas berkisar $1322 \Omega \mathrm{m}-2348 \Omega \mathrm{m}$ dapat diasumsikan sebagai batuan andesit. Lintasan 6 adalah lintasan yang mengarah ke utara dan memotong lintasan 1,2,3, dan 4 serta memiliki permukaan topografi yang relatif datar terhadap permukaan tanah. Batuan beku yang didapatkan dari hasil pengukuran nilai resistivitas pada lintasan ini adalah batuan beku jenis andesit dengan rentang nilai resistivitas berkisar $1322 \Omega \mathrm{m}-2348 \Omega \mathrm{m}$, dengan rentang nilai pada tabel resistivitas $100 \Omega \mathrm{m}-10000 \Omega \mathrm{m}$. Batuan ini terdapat pada rentang $10 \mathrm{~m}-150 \mathrm{~m}$ dari kedalaman $1,25 \mathrm{~m}-12,4 \mathrm{~m}$ dan pada rentang $80 \mathrm{~m}-100 \mathrm{~m}$ di kedalaman $6,38 \mathrm{~m}-28,7 \mathrm{~m}$ dibawah permukaan tanah.

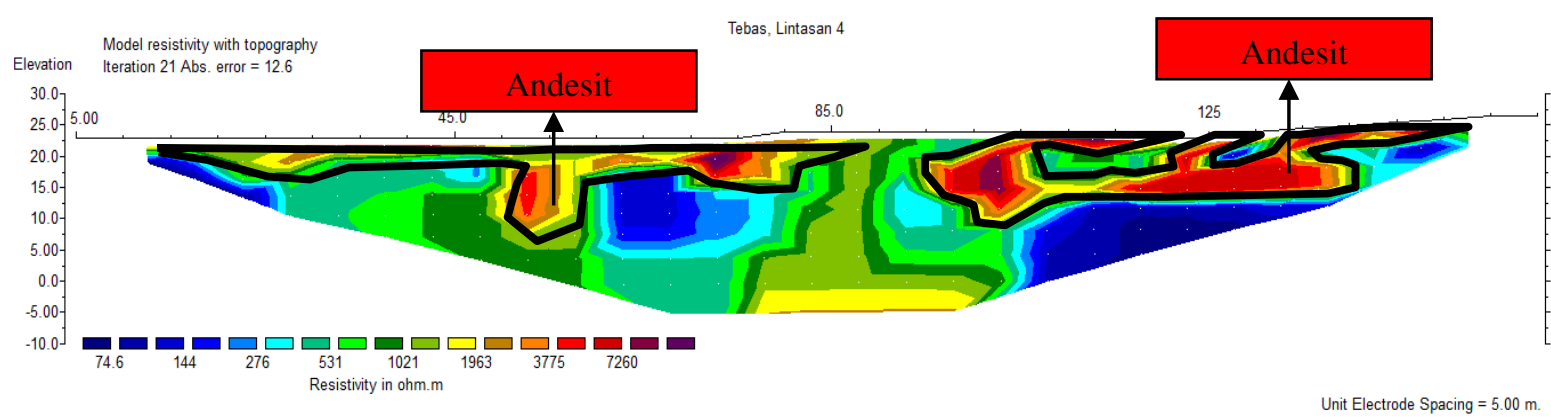

Gambar 8. Penampang resistivitas pada lintasan 4 


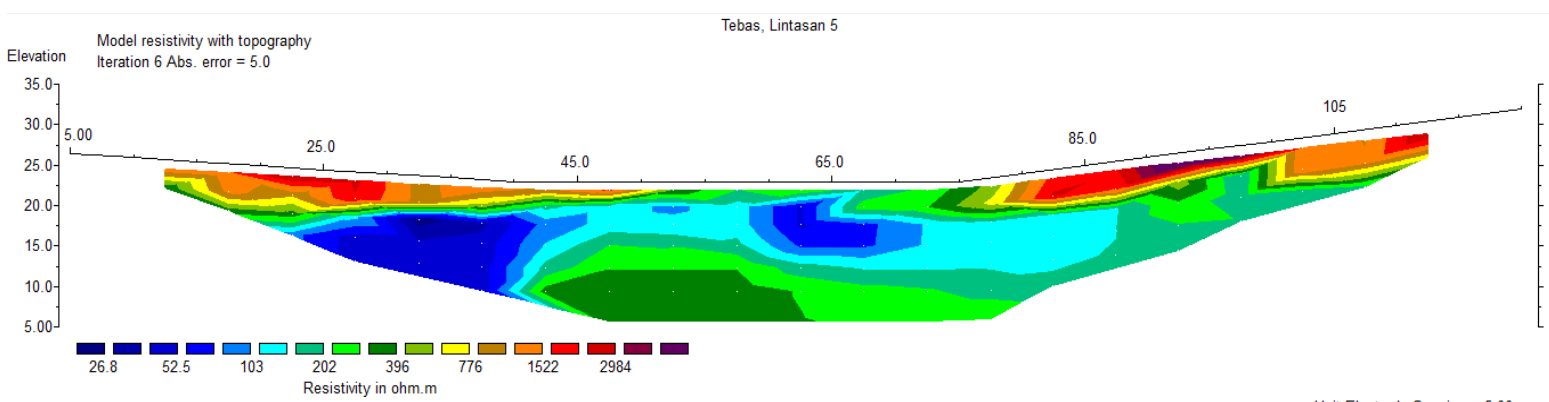

Gambar 9. Penampang resistivitas pada lintasan 5

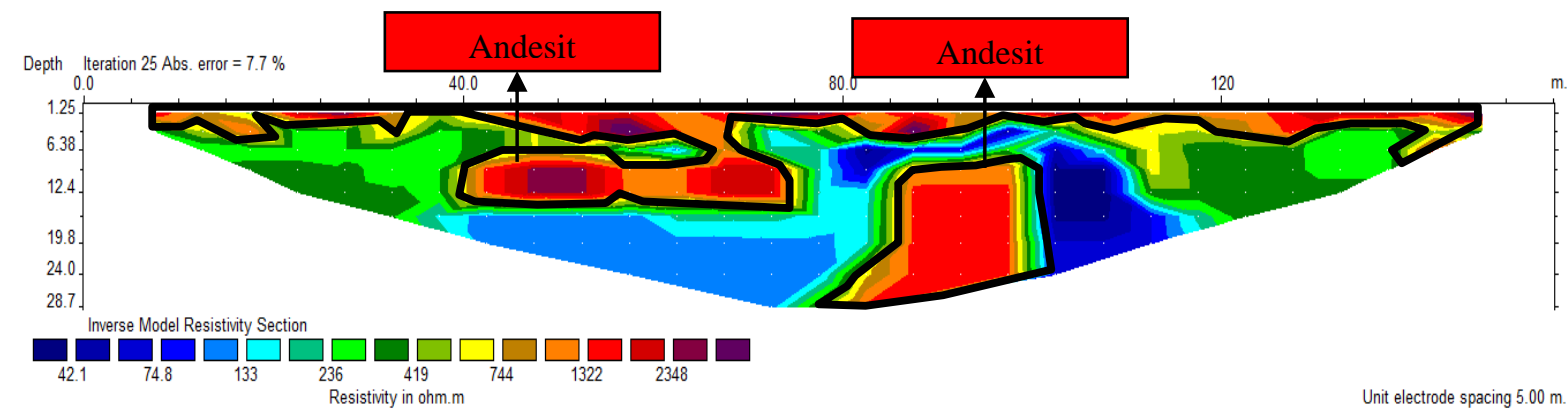

Gambar 10. Penampang resistivitas pada lintasan 6

\section{Kesimpulan}

Berdasarkan hasil analisis data geolistrik dan hasil interpretasi, maka dapat disimpulkan bahwa jenis material di lokasi penelitian di Bukit Koci Desa Sempalai Kabupaten Sambas Kalimantan Barat yang didapatkan adalah lempung, pasir, batu pasir, dan batu andesit.

\section{Daftar Pustaka}

[1] Novia E, Akmam , Mufit F. Identifikasi jenis batuan menggunakan metode geolistrik tahanan jenis konfigurasi wenner di universitas negeri Padang kampus Air Tawar. Pillar of Physics. 2013; 2: p. 01-08.

[2] Ulien N, Khuamedi , Supriyadi. Pemodelan Fisis Aplikasi Metode Geolistrik Untuk Identifikasi Fosfat Dalam Batuan Gamping. Unnes Physics Journal. ; II: p. 83.

[3] Hendrajaya L, Arif I. Metode Geolistrik Tahanan Jenis Bandung: Laboratorium Fisika Bumi Jurusan Fisika FMIPA ITB; 1990.
[4] Singh KB, Lokhande RD, Prakash A. Multielctroda Resistivity Imaging Tecnique For The Study of Coal Seam. Jounal of Scientific and Industrial Research. 2004; LXIII: p. 927-930.

[5] Herman R. An Introduction to Electrical Resistivity in Geophysics. Journal of America Association of Physics Teachers. 2001; LXIII: p. 943-952.

[6] Telford WM, Geldart LP, Sheriiff RE, Keys DA. Applied Geophysics London: Cambridge University Press; 1990.

[7] Sakka. Metode Geolistrik Tahanan Jenis Makassar: Fakultas Matematika dan Ilmu Pengetahuan Alam Universitas Hasanuddin; 2001.

[8] Sempalai. 1'14'50.06"N and 109¹0'1.90"E. Google Earth. May 5, 2015 19, 2016.

[9] Waluyo. Buku Panduan Workshop Geofisika Yogyakarta: Laboratorium Geofisika Program Studi Geofisika UGM; 2005. 